"The EUrASEANs: journal on global socio-economic dynamics"

Volume 4 (11); July-August, Year 2018;

ISSN 2539 - 5645 (Print)

Copyright (C) 2018, [The EUrASEANs]

on-line access: https://www.euraseans.com/4(11)

\title{
E-BUSINESS AND INTERNET ADOPTION IN HEALTHCARE
}

\author{
Mahdia Binta Kabir \\ Irina V. Onyusheva \\ Stamford International University, Bangkok, Thailand
}

In this article changing trends and newer challenges at the global market in the context of a wellstructured and well-established business. One of the most topical trends for today is to have the most efficient information system technology available for your business. The world is bursting with different kinds of information. But a well-designed information system will always help strategic planners in selecting and using proper information in the course of decision-making. Recent studies showed rapid growth of e-businesses across the world. Internet as an information-rich resource that to a large extent predetermines communication ways and means today, thus making all other functions much easier for organizations of all sizes and sectors. Healthcare industry is no different in this regard. The quicker any organization can adopt the integrated use of internet, the more efficient it will become.

Keywords: Internet, e-business, information system, healthcare sector.

\section{Introduction}

In today's highly competitive world, in order to improve healthcare organizations have to adapt to many changes, starting with advances in diagnostics and therapeutic procedures and finishing with administrative innovations such as managed care and the latest information technologies and systems.

The Internet represents a particularly profound change that, in its turn, enables many other significant changes in organizational forms and processes. The Internet's not only empowers consumers, it supports dynamic information exchange among organizations and "flatten" organizational hierarchies, promising more results from new operational strategies,

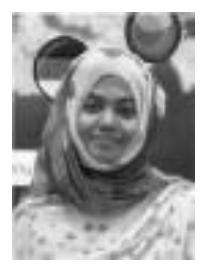

\section{Mahdia Binta Kabir}

International MBA Program, Stamford International University, Bangkok, Thailand Interests - International Business Management, Strategic Management, Strategic Marketing

Email: mahdia.anni645@gmail.com

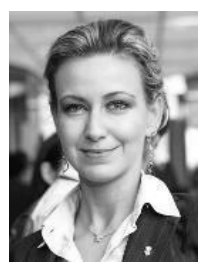

\section{Irina V. Onyusheva}

Stamford International University, Dr., Prof. Interests - Economics, Strategic Management, Formation, ensuring and increasing economic competitiveness on both micro- and macro- levels; Human Capital development; HR Management; Knowledge Economy; Knowledge Management; Project Management; Management in Education

E-mail: irina.onyusheva@stamford.edu 
sophisticated business models, new service delivery modes, revised management mechanisms etc.

All these changes will have far-reaching implications, therefore, healthcare organizations need to start preparing already now to adopt themselves to the advanced Internet applications that are expected to appear in the near future. Organizations need to evaluate their potential and implications of new Internet technologies, adapt already available technologies and apps to the local needs and conditions, thus minimizing the risks associated with new product and service deployment. This paper examines the challenges related to the adoption of Internet-based technologies by healthcare organizations.

\section{Problem Context}

The Internet has been a trendy research topic for a while already. However, most of the related research studies focus on Europe or America rather on than Asian countries. This study hopes to contribute to better understanding of the Internet phenomenon in Asia by examining the factors influencing the adoption and non-adoption of the Internet among organizations in Singapore. A survey was carried out among business firms to examine the benefits of adopting the Internet, reasons for not adopting it, and the criteria for selecting Internet service providers.

The results showed that the key benefits are usually derived from the global nature of the Internet since it enables access to information worldwide. Non-adopters of the Internet are most frequently concerned that their staff will be wasting time surfing the Internet instead of working. Both speed of access and technical support are viewed as important criteria in selecting an Internet access service provider (IASP).

Healthcare organizations also attempt to identity the fundamental impediments to greater use of the Internet. The discussion here addresses internal and external factors, such as policy and technical barriers, promoting or constraining the forms and the extent of Internet use, as well as the range of uncertainties that inhibit decision-making regarding the use of Internet.

\section{Research Goal and Objectives}

The main goal of this research is studying of the adaptation capabilities of organizations in relation to such phenomenon as the Internet. To achieve this broader research goal the following objectives have been identified:

to study the flexibility to newer changes, in this case, the Internet in a variety of its manifestations;

to analyze the adaptability to the Internet by the care-providing organizations; to describe the flow of communication in this context.

\section{Research Methods}

The research methods applied here include comparative and systemic analyses, causes and consequences analysis, methods of statistic grouping and expert assessment.

The research model is shown in Fig. 1. 


\section{E-BUSINESS AND INTERNET ADOPTION}

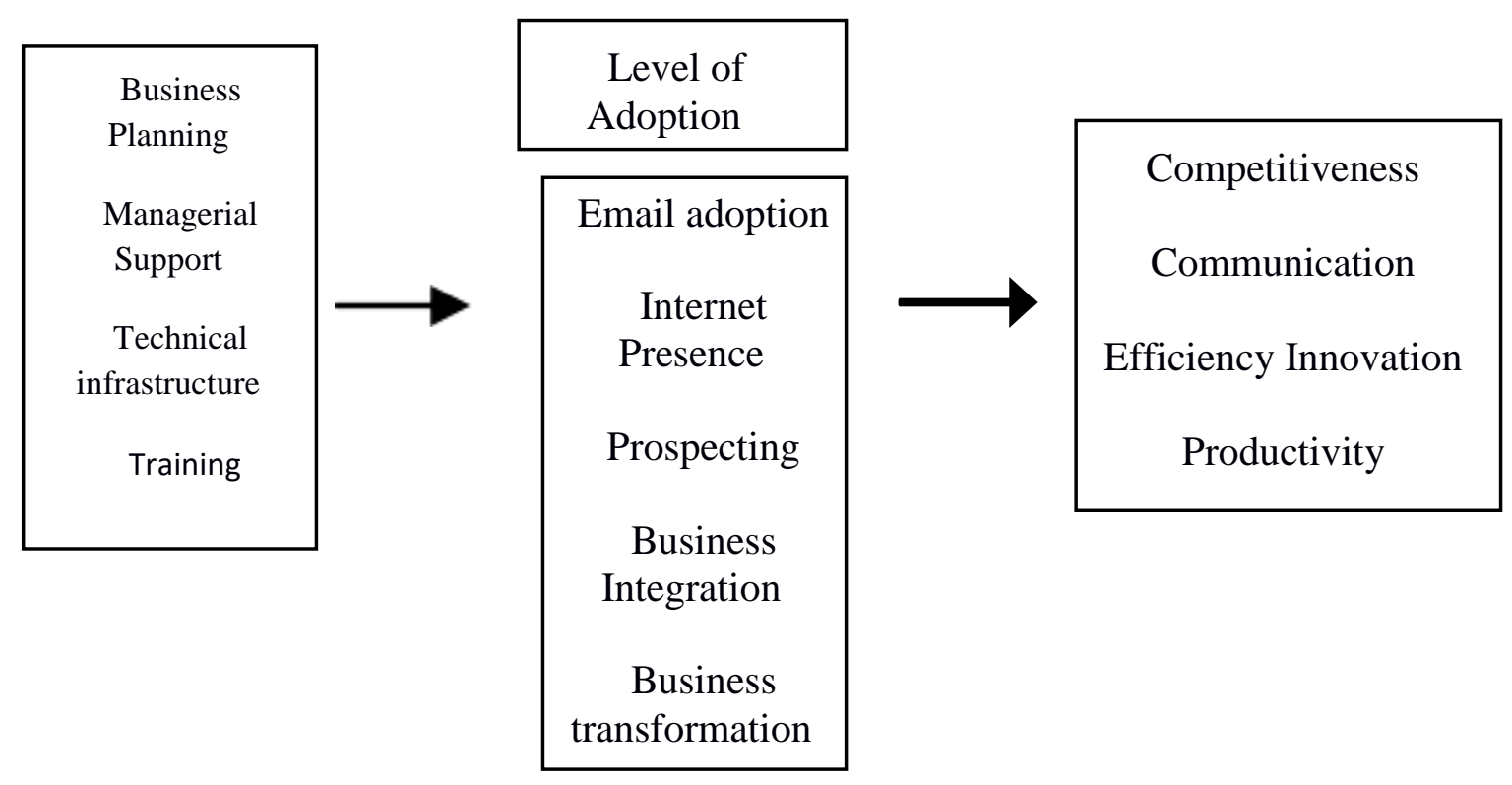

Figure 1. Factors and impacts of the Internet adoption (designed by the coauthors)

The level of adaptation is influenced by such factors as business planning, managerial support, technical infrastructure and proper training. Together they eventually result in competitiveness, communication, efficiency, innovation and productivity.

There are several level of the Internet adoption. More details on each of them are provided below.

Level 0: E-mail adoption

A company on level 0 is the one that has an e-mail account but does not have a web site (yet). The inclusion of level 0 is based on the research (Teo et al., 1997-1998) which classified Internet adoption into three groups: non-adopters (not using Internet at all), adopters without web sites but with an Internet account, and adopters with own websites.

Level 1: Internet presence

The first level of Internet adoption is Internet presence. At this level, companies have already made the adoption decision but the implementation is still in process (similar to Category 2 (planning to adopt) as in Sohn \& Wang (1998, 1999), or the level 1 (Static) as in (AMS, 1999). The purpose of adoption may be to have own domain name or simply to have Internet presence, thus, be visible online.

Generally, the websites created at this level of the Internet adoption provide mainly basic information on the company, its activities and/or contact details, therefore, we can state that the information provided is non-strategic in nature.

Level 2: Prospecting

The second level of Internet adoption is called prospecting. It involves the limited use of the Internet (similar to Category 3 (limited users) as suggested by Sohn \& Wang (1998, 1999) or level 2 (Interactive) as in (AMS, 1999). Usually, Internet adoption initiatives at this 
level are spearheaded by individual departments and are not tied to the core business strategy. Most firms at this level organize their websites so that to provide customers with detailed information on the company itself and its product(s) along with some news, events, interactive content, personalised content, e-mail support, and simple search. This strategy is helpful in providing current and potential customers with access to the firm's products with minimal information distribution cost.

Level 3: Business integration

The third level, called business integration, takes into account the integration of business processes marked by the incorporation of the Internet into the business model. In other words, the Internet adoption strategy is integrated into the general firm's strategy of business development. At this level, the key functions of a website are usually cost reduction and business support, as well as setting cross-functional links with customers and suppliers. Noteworthy here, as compared to the first two levels, websites at this level are more complex with added features for interactive marketing/sales, online communities and secure transactions of payments (very similar to level 3 (Transactive) in (AMS, 1999)).

Moreover, the features already found at levels 1 and 2 are enhanced at this level, for example, the information provided on the website is more comprehensive and the search function carries more advanced and powerful properties.

Level 4: Business transformation

The fourth level aims to transform the business as such and represents the highest level of the Internet adoption. The Internet is seen to transform the overall business model by focusing on building the relationships and seeking new business opportunities (similar to level 4 (Intelligent) in (AMS, 1999)).

Levels 3 and 4 are also similar to Category 4 (sophisticated users by Sohn \& Wang, 1998, 1999) except that we split sophisticated users into two separate levels consistent with the maturity model (AMS, 1999).

Thus, the level of Internet adoption will define the level of impact on the organization. The higher level the organization can reach in adaptation - the more effective will be these impacts. In this regard, questionnaires should be sent to various healthcare organizations to identify their level of adoption and to analyze it in detail.

\section{Adoption}

Adoption of the Internet is not restricted to certain industries. There is an increasing trend of massive Internet adoption by firms, regardless their industrial affiliation and/or size, simply because websites can really help all firms reach out to the maximum numbers of potential customers. However, firms with higher market performance (usually measured by revenues) are more likely to use websites to reach out to their customers as compared to other firms (Liu et al., 1997).

Contingency factors affecting Internet adoption are likely to include both internal and external factors (Santos \& Peffers, 1998; Vadapalli \& Ramamurthy, 1998). Organisational factors usually include: technological policy, top management support, and top management risk position; compatibility and relative advantage; while environmental factors cover such issues as competition intensity, information intensity and government support.

The results show that organizational factors have stronger relationships with Internet adoption level as compared to environmental factors (Teo et al., 1997-1998). In a similar 


\section{E-BUSINESS AND INTERNET ADOPTION}

vein, research on the IS adoption has found that businesses with certain CEO characteristics (innovativeness and individual level of IS knowledge), innovation characteristics (relative advantage, compatibility and complexity of IS), and organizational characteristics (business size and level of employee's IS knowledge) are more likely to adopt IS.

CEO's features nearly always affect the decision to adopt but not the extent of adoption while competition seems to have no direct effect on adoption. The extent of adoption is mainly determined by organizational characteristics (Thong, 1999). Other research has examined the impact of IT on competitiveness. For example, electronic linkages, such as inter-organizational systems and Internet-based commerce, are powerful ways to facilitate cost leadership and differentiate products and services.

Lederer et al. (1997) examined the relationship between a firm's electronic commerce strategy and a general business strategy, suggesting that firms perceive differentiation but not cost leadership as a benefit of electronic commerce. Firms that make IS investments in response to pressure from customers or initiatives of competitors may quickly gain strategic advantage over other competitors that fail to do so. Further, trading partner relationships and the balance of power are critical issues for the firms participating in electronic commerce. Large firms often initiate electronic data exchanges due to competition and the need to bring in extra efficiency into day-to-day operations.

On the other hand, these firms are also interested in boosting their size in order to influence the supply chain and sustain a dominant position. Thus, large firms are forcing smaller firms to adopt electronic data exchange and other information tools and systems (Young et al., 1999). Imitation and communication among industry competitors are important factors for the adoption of new technologies (Santos \& Peffers, 1998).

The value of a technology is dependent upon its adoption and acceptance by relevant parties. The benefits to early adopters are often affected by the adoption timing decisions. If other firms in an industry are slow to imitate the IT innovation, the benefits of early adopters can be a significant addition. Adoption decisions also determine whether technologies eventually become the industry's standards or they will be substituted by other, similar technologies. In summary, the adoption of the Internet is influenced by various contingency factors, all having a wide range of impacts on firms.

However, not all contingency factors are equally important. Similarly, the impact of adopting the Internet does differ among firms.

\section{Things to consider from other industries}

Internet technologies offer a range of potentially useful applications to organizations in many different industries and fields of human activity. Simple Internet applications such as electronic mail (e-mail) can facilitate communication within multinational corporations, for example. Network-based applications can simplify the flow of information among different elements of the same organization andor among multiple organizations. Real-time teleconferencing technologies support communications and business operations involving individuals located in different cities/countries/continents.

Direct capture of sales information can enable retailers streamline the delivery of inventory and forecast purchasing patterns. New automation systems allow for distributed management of supply chains, support of human resource functions, and exchange of contact and other useful for sales information. Although deployment of these systems is still at an 
early stage in some many countries worldwide, Internet technologies appear to have enhanced organizational impacts due to lowering costs, increasing efficiency, differentiating products and services, and even through markets' expansion.

Industries differ in many respects, and their degree of success achieved in applying the Internet varies as well. However, experiences of leading companies from different industries in which Internet use is common suggest a number of general trends. For example, the Internet is clearly transforming the retail marketplace.

Online retailers such as Amazon.com and Barnes \& Noble have changed the nature of the book industry by creating direct relationships between book buyers and book suppliers. The latter managed to reduce significantly their inventory costs and eliminate many middle layers in the distribution chain - a process now often called disintermediation.

Manufacturers of personal computers, such as Dell, are increasingly using the Internet to market their wares directly to consumers, thus enabling consumers customize their orders individually and also enabling firms control inventory at the lowest possible levels.

Online auction sites, such as eBay, have pioneered new ways to link buyers and sellers in a virtual marketplace, with so many companies expanding on the auction concept so that to exploit the so-called spot markets of last-minute airline tickets, car rentals, hotel rooms, and other services.

Internally, effective use of information technology (IT), including Internet, can have a profound impact on organizational structure and functions. As information is distributed efficiently to those who need it when they need it, the lines of control and influence become clearer, and individual units often self-organize in new and more effective ways. The impact may be multifaceted, not only flattening the organizational structures but also changing the skills' mix of employees.

Evidence from as early as 1990s suggests that online sales of automobiles reduce the set of skills needed by salespeople (McGarvey, 1999). In contrast, some stock brokerage firms report that online trading requires brokers to have a broader set of skills, although the total number of brokers needed may decline because a significant part of the efforts needed for stock transaction can be passed onto consumers.

Online interactions boost consumer expectations. Many traditional storefront industries - from retail to news - are now open around the clock, competing in a highly visible and competitive environment. Consumers conduct many transactions at night or on holidays, when many traditional merchants are closed. Moreover, in a highly transparent environment buyers often compare the prices of many Internet vendors before making the actual purchase. In fact, many Internet companies encourage consumers to discuss topics or items of their immediate business interest. Internet book merchants, for example, allow readers contribute reviews and rate the quality of the offers. Internet-based vendors of financial information sometimes support client-generated discussion groups on specific equities or investing techniques. These and other tools are intended to assist consumers in making more grounded decisions and, simultaneously, attract them to particular sites.

Internet technologies also allow merchants develop a deeper understanding of consumers, their attitudes and preferences. By automatically recording consumer choices, online merchants can offer both goods and advertising that have higher likelihood of reaching a desired consumer audience. If applied successfully, these technologies enable merchants develop a sense of one-to-one personalized service for thousands or even millions 


\section{E-BUSINESS AND INTERNET ADOPTION}

of customers - a process sometimes called mass customization. Vendors can even allow consumers preview or experiment with products prior to the actual purchase.

The film industry now routinely provides previews of upcoming movies on companies' websites, for example. The music industry also distributes a variety of promotional materials online in the hopes of generating more revenue from traditional sales later on. Online mortgage vendors allow consumers simulate the cash-flow implications of various mortgage packages.

Most importantly, customer relationships established by successful Internet companies are not static. Rather, companies evolve in parallel to changes in their customers' needs and in the level of technologies' sophistication. Active empowerment of consumers forces companies provide highly targeted services and a degree of variety commensurate with buyers' needs. During this period of rapid Internet evolution, companies are literally reinventing their online demeanor on a weekly basis in response to changing perceptions developed through experimentation with the Internet. In essence, merchants and consumers are engaged in a consensual exploration of the means by which this technology can more effectively satisfy perceived mutual needs.

\section{Recommendation}

Healthcare organizations will not increase their commitment to Internet-based applications without strong leadership support. Leadership vision is always the most crucial determinant in successful use of applications and information technologies in general. Limited, narrowly focused applications may be implemented at the grassroots level in an organization and successfully applied, but when applications require complex interactions across - and potentially beyond - the organization, skills and talents of individual participants must be supported by strong institutional leadership and a shared vision of what the organization is trying to accomplish regarding this problem specifically.

Until the 1980s, IT managers working for major corporations typically played a technical, service-oriented role solely. They brought in their technical skills plus partially management abilities. Today, however, the strategic role of information systems has become very much obvious as corporations plan for the future, identify new business opportunities, and implement new practices for communicating with clients, distributing products, and managing inventories and finances. As a result, IT managers are increasingly identified as some sort of strategic leaders within their organizations, and healthcare industry is no exception in this regard.

Their titles have evolved too, up to chief information officer (CIO) or even vice president for information systems and technology. And this is yet another reflection of their central role within businesses and organizations. When their roles were considered to be purely technical rather than strategic, they often reported to the chief financial or administrative officer. Today, however, they typically report directly to the chief executive officer (CEO) and even participate directly and actively in high-level strategic planning, priorities' setting and strategic decision-making.

In fact, Peter Drucker has gone in this regard so far as to suggest that information and supporting technology is becoming so central to the strategy that the CEO of the future will be the CIO (Drucker, 1999). 
Another important change that has occurred during the past two decades is as follows. Originally the IT leader within an organization had very little industry-specific expertise (e.g., CIO in a healthcare company would typically have no medical or pharmaceutical background). Their responsibilities were largely confined to managing large-scale technical installations and implementations, and IT activities as such were viewed primarily as a cost center for the organization. It is now axiomatic in many industries, however, that the CIO has deep industry expertise. Ideally, IT leaders "grow up" within the industry and combine domain training and/or expertise with an inclination towards information systems. Rather than constituting a cost center, the IT functions overseen by the CIO are increasingly viewed as enablers of the key business or the source of strategic opportunities.

Several studies across a range of industries have demonstrated a relationship between the effectiveness of an organization's application of IT and the presence of a senior, strategy oriented IT executive (CHIME, 1998; Earl and Feeney, 1995; Kilbridge et al., 1998; McKenney et al., 1995; Ross et al., 1996; Sambamurthy, 1996). Effective use of the Internet is unlikely to be an exception here.

In healthcare, the pre-1990 model still lingers, with CIOs often having limited experience in the medical environment. Expectations from this post still do not assume any sort of a strategic role and instead suggest a predominantly service and infrastructure orientation. This is true for all industry levels, from community-based hospitals to large biomedical research universities.

The reporting level and the professional background of the information strategy leader in an organization inevitably influence the attention the information management receives, thus, the latter can really affect the types of initiatives to be undertaken. A CIO with a background in clinical medicine might place higher priority, for example, on the establishment of EMRs and decision-support systems, and the same can hardly be expected from a CIO with a strictly technical background.

This is not to suggest that every information strategy leader in health care needs to be clinically trained. What is critical to keep in mind is that the CIO function as a professional peer of the organization's senior leadership. This individual certainly requires deep understanding of the business mission of the organization and he/she should certainly have place at the table whenever strategic decisions are being made.

Healthcare organizations need to recognize the importance of IT management. Certainly there are important educational issues involved here: healthcare leaders must be familiarized with the fundamental role the IT needs to play in their organizations, and they also must be ready to expand their IT staff list in the near future already. CIOs, ideally, must be brought up from within healthcare organizations so that to have a combination of technical and management skills as well as medical knowledge.

Effective use of the Internet by the healthcare sector would certainly require significant investment and commitment of medical organizations overall and their visionary leadership in particular. Understanding the strategic role of technologies today is certainly able to guarantee return on investment.

\section{Conclusion}

Inclusive growth in the numbers of Internet users requires today a multipronged strategy - the one that will depend on close collaboration among various players across the 


\section{E-BUSINESS AND INTERNET ADOPTION}

globe, including governments, policy makers, NGOs, network operators, device manufacturers, content and service providers, brands owners and other stakeholders. Research in several related areas at the same time could give healthcare organizations enough confidence they need to move forward in using the Internet. First and foremost goes research on Internet-induced changes in healthcare economics, in organizational forms of healthcare business and the related interorganizational processes. This could provide better guidance for organizations and patients, helping both to ensure that all related changes are effective and that they do not damage the healthcare system or health of patients as consumers of the related services.

Policies and procedures directly related to effective management of Internet-related clinical, administrative, and fiscal processes and activities would help organizations address these issues before they become real problems. Assessment of the Internet's capability to resolve (or not) the healthcare system's persistent difficulties with implementing and managing older information technologies would provide guidance on the value added. Case studies on the staffing and the skills needed to be developed and supported for the use of Internet-based applications could assist in further planning on the use of Internet tools by healthcare organizations.

Poorly conceived or poorly executed change could have seriously negative consequences for the healthcare of the whole nation, including healthcare organizations, healthcare R\&D as well as health of all citizens. Thus, further research in this direction is most certainly needed for developing better guidance on positive transformations of the healthcare industry.

\section{References:}

Tan, M., \& Teo, T. S. (n.d.). Factors Influencing the Adoption of the Internet. Retrieved September 25, 2017, from http://www.tandfonline.com/doi/abs/10.1080/10864415.1998.11518312

National Research Council (US) Committee on Enhancing the Internet for Health Applications: Technical Requirements and Implementation Strategies. (1970, January 01). Organizational Challenges to the Adoption of the Internet. Retrieved September 25, 2017, from https://www.ncbi.nlm.nih.gov/books/NBK44715/

Teo, T. S., \& Pian, Y. (2003). A contingency perspective on Internet adoption and competitive advantage. European Journal of Information Systems, 12(2). 78-92. doi:10.1057/palgrave.ejis.3000448

Offline and falling behind: Barriers to Internet adoption. (n.d.). Retrieved September 26, 2017, from http://www.mckinsey.com/industries/high-tech/our-insights/offline-and-falling-behindbarriers-to- internet-adoption

Choo, W. Y., \& Teo, T. S. (n.d.). Assessing the impact of using the Internet for competitive intelligence. Retrieved September 26, 2017, from https://zdoc.site/assessing-the-impact-ofusing-the-internet-for-competitive-i.html

Paper submitted

Paper accepted for publishing

Paper published online
19 April 2018

22 May 2018

31 July 2018 